\title{
LOS DERECHOS HUMANOS Y EL MAGISTERIO DE LA IGLESIA DURANTE LA GRAN GUERRA DEL SIGLO XX ${ }^{1}$
}

\author{
Human Rights and the Magisterium \\ of Catholic Church During the Great War \\ of the Twentieth-Century \\ Os direitos humanos e o magistério \\ da Igreja durante a grande guerra do Século $X X$ \\ Juan David Velásquez Monsalve²
}

1 Este texto hace parte del trabajo de investigación "Los Derechos Humanos y la Iglesia Católica. Un recorrido por el Magisterio Pontificio desde León XIII hasta Juan Pablo II”. Trabajo de grado con el cual el autor optó por el título de Teólogo en la Universidad Católica de Oriente.

2 Abogado de la Facultad de Derecho y Ciencias Políticas de la Universidad Pontificia Bolivariana (UPB) de Medellín. Teólogo de la Universidad Católica de Oriente (Rionegro, Antioquia). Candidato a Magíster en Filosofía de la UPB. Ha sido profesor de la cátedra de Filosofía del Derecho en la Universidad Católica de Oriente. Actualmente se desempeńa como Rector del colegio Sagrado Corazón Montemayor. Correo electrónico: juandvelasquezm@gmail.com

Artículo recibido el 1 octubre de 2015 y aprobado para su publicación el 1 marzo de 2016. 


\title{
Resumen
}

En los últimos dos años hemos conmemorado varios acontecimientos importantes que marcaron la historia contemporánea: en el año 2014, el centenario del inicio de la Primera Guerra Mundial; en el 2015, los setenta años de la finalización de la Segunda Guerra Mundial; también recordamos con escozor el descubrimiento de los campos de concentración nazis. En este artículo nos ocuparemos de reflexionar acerca del pensamiento de los Sumos Pontífices de la Iglesia Católica durante los años de las Guerras Mundiales, que algunos autores han catalogado con acierto como la Gran Guerra del siglo XX. Después de estudiar diversos documentos expedidos por los Papas de estos años (cartas encíclicas, declaraciones, discursos y radiomensajes) se puede llegar a la conclusión de que en el pensamiento de Benedicto XV, Pío XI y Pío XII existió una gran preocupación por la defensa de los Derechos Humanos, la cual no solo se limitó a promulgar una teoría acerca de los Derechos y su fundamento, sino que se plasmó en una férrea defensa del ser humano y de su dignidad, denunciando con valor los atentados contra los Derechos Humanos que cometían las ideologías, comprometiéndose con la búsqueda de la paz mundial y protegiendo a los débiles y perseguidos injustamente por dichos regímenes.

\section{Palabras clave}

Derechos humanos, Guerras Mundiales, Dignidad humana, Benedicto XV, Pío XI, Pío XII.

\begin{abstract}
During the last two years we have commemorated several significant events that left a mark in Contemporary History: in 2014, the First World War Centenary; in 2015, the 70 ${ }^{\text {th }}$ anniversary of the End of World War II; and also the anniversary of the discovery of the Nazi Concentration Camps. The purpose of the article is to review the thought of the Popes during the years in which the World Wars took place. After reviewing different documents produced by the Popes during those years (e.g., encyclicals, statements, speeches and radio broadcasts), it is concluded that the thought of Benedict XV, Pius XI and Pius
\end{abstract}


XII was characterized by a concern for the protection of Human Rights. Such concern was not only limited to a theoretical reflection about the Rights and their grounds, but also was reflected in a fierce defense of human beings and their dignity, by expressing complaints about the violation of Human Rights committed by ideologies, a commitment to achieve World Peace, and by protecting those who were unfairly persecuted by political regimes.

\section{Keywords}

Human Rights, World Wars, Human Dignity, Benedict XV, Pius, XI, Pius XII.

\section{Resumo}

Nos últimos dois anos comemoramos vários acontecimentos importantes que marcaram a história contemporânea: em 2014, o centenário do início da Primeira Guerra Mundial; em 2015, os setenta anos do término da Segunda Guerra Mundial; também recordamos com desagrado o descobrimento dos campos de concentração nazistas. Neste artigo trataremos de refletir sobre o pensamento dos Sumos Pontífices da Igreja Católica durante os anos das Guerras Mundiais, que alguns autores catalogaram com acerto como a Grande Guerra do século XX. Depois de estudar diversos documentos expedidos pelos Papas destes anos (cartas encíclicas, declaraçóes, discursos e radio-mensagens), pode-se chegar à conclusão de que no pensamento de Bento XV, Pío XI e Pío XII existiu uma grande preocupação pela defesa dos Direitos Humanos, a qual não só se limitou a promulgar uma teoria acerca dos Direitos e seu fundamento, mas que se plasmou em uma férrea defesa do ser humano e sua dignidade, denunciando com coragem os atentados contra os Direitos Humanos que cometiam as ideologias, comprometendo-se com a busca da paz mundial e protegendo os débeis e perseguidos injustamente por tais regimes.

\section{Palavras-chave}

Direitos Humanos, Guerras Mundiais, Dignidade Humana, Bento XV, Pío XI, Pío XII. 


\section{INTRODUCCIÓN: LA VOZ DE LA IGLESIA DURANTE LA GRAN GUERRA}

Muchas veces en consonancia con el sentir de la época y otras tantas en contra de los gobiernos y doctrinas de turno, la Iglesia católica ha proclamado la inmensa grandeza y vocación del ser humano a lo largo de los siglos. El pensamiento católico sostiene que la grandeza de la dignidad del hombre se basa sobre todo en el hecho de haber sido creado por Dios a su imagen y semejanza; de haber sido reconciliado por el Señor Jesús a pesar de la ruptura inicial; de que el mismo Jesús le enseña la sublimidad de su vocación y de estar llamado a gozar de la presencia de Dios por toda la eternidad. Estas profundas convicciones están presentes tanto cuando la Iglesia anuncia al mundo la dignidad humana y sus derechos, como cuando denuncia las injusticias que se comenten en su contra.

En un tiempo en el que con dolor y tristeza hemos recordado el centenario del inicio de la Primera Guerra mundial y los setenta años del descubrimiento de los campos de concentración nazis en Auschwitz, que con terrible crueldad operaron durante los años de la Segunda Guerra mundial, resulta iluminador recordar la voz que elevaron los Sumos Pontífices de cada época. Dicho Magisterio, muchas veces desconocido, resulta esclarecedor para quien quiera profundizar en la importancia de fundar los derechos humanos sobre bases seguras.

En este trabajo abordaremos el Magisterio de Benedicto XV, quien asumió la Sede de san Pedro desde 1914 hasta 1922. En su rico Magisterio nos encontramos con la angustia de un hombre que clama por la paz en medio de un desierto de indiferencia y de odio desenfrenado. Benedicto XV se esfuerza no solo por señalar las raíces de la guerra, sino también por recordar cuáles deberían ser las bases para un paz real y duradera. Pocos gobernantes escucharon su voz, sin embargo, el tiempo evidenciaría que no le faltaba razón al Papa della Chiesa, pues una paz mal firmada y no afincada en la justicia llevaría, tarde o temprano, al desencadenamiento de un nuevo conflicto.

A Benedicto XV lo sucede Pío XI, quien estará al frente de la Iglesia católica de 1922 hasta 1939. No son tiempos fáciles los que le tocan al Papa Ratti. Durante la tensa calma de estos ańos van creciendo en poder y en adeptos el fascismo italiano y el nazismo alemán. Ante estas terribles 
ideologías, el Papa Pío XI alertará al mundo, desafortunadamente sin mucho eco. Lo mismo hará frente a la ideología comunista que regía en la Unión Soviética y que ya evidenciaba su poco respeto hacia la dignidad y los derechos humanos. En medio de la falsa paz que se vivía en Europa estalla la guerra civil en España precedida de una injusta y cruel persecución religiosa. Pío XI fallece ad portas del reinicio de la Gran Guerra, tan solo unos meses antes de que comenzara la Segunda Guerra Mundial.

Pío XII asume el Solio Pontificio en el umbral de la tormenta que se desataría bajo el lema Pax opus iustitie (la paz es obra de la justicia). Su grito agónico “iNada se pierde con la paz, todo puede perderse con la guerra!" será el último llamado pronunciado antes de la Guerra. Temibles y dolorosos años marcan el inicio de este pontificado. Pacelli, el experto diplomático, hará gala de sus capacidades para mantener contacto con todas sus nunciaturas en medio del conflicto y de esta manera poder ayudar a los que más pudiera. Muchos historiadores, entre ellos judíos, dan cuenta de las miles de personas del pueblo hebreo que salvaron su vida gracias a la ayuda del Papa Pío XII. En medio de esta estrategia diplomática, el Papa exhortará sin cansancio a la búsqueda de la paz. Una paz que para ser duradera y real debía fundarse en la justicia.

\section{BENEDICTO XVY LA PRIMERA GUERRA MUNDIAL}

El 6 de septiembre de 1914 el entonces arzobispo de Bolonia, el cardenal Giacomo della Chiesa es elegido Sumo Pontífice de la Iglesia Católica. Con el nombre de Benedicto XV (1914 - 1922) se convierte en el sucesor de Pío X. Su pontificado estará marcado por la terrible tempestad que se desata en Europa durante la Primera Guerra Mundial, así como también por el constante llamado a la paz y a la reconciliación entre las naciones. Se puede afirmar con Alberto Martín Artajo (1958) que "el pontificado de Benedicto XV presenta, desde el punto de vista de la reconciliación cristiana de los pueblos, la misma importancia que tuvo el de León XIII desde el punto de vista de la reconciliación cristiana de las clases sociales" (p. 437). El Papa della Chiesa se dedica a luchar por una paz justa, fruto de un orden internacional justo que promueva la reconciliación y la convivencia entre las naciones. 
Varias encíclicas marcan este camino de esfuerzo por la paz mundial. En su primera carta Ad beatissimi escrita en noviembre de 1914, tan solo unos meses después de haber estallado el conflicto en el continente europeo, el Papa enuncia las causas que considera la raíz de la guerra:

La ausencia de amor mutuo en la comunicación entre los hombres; el desprecio de la autoridad de los que gobiernan; la injusta lucha entre las diversas clases sociales; el ansia ardiente con que son apetecidos los bienes pasajeros y caducos (...) en estos cuatro puntos se contienen, según nuestro parecer, otras tantas causas de las gravísimas perturbaciones que padece la sociedad humana (Benedicto XV, 1914, n. 4).

Antes que las causas políticas, el Papa considera que el desprecio y el maltrato a la persona humana y, en consecuencia, a sus derechos elementales son la verdadera causa del conflicto europeo. Benedicto XV, después de lamentarse por los dramáticos hechos, hace un enérgico llamado a recurrir a los medios que el derecho brinda para solucionar los conflictos: "Que nos escuchen, rogamos, aquellos en cuyas manos están los destinos de los pueblos. Otros medios existen, ciertamente, y otros procedimientos para vindicar los propios derechos, si hubiesen sido violados. Acudan a ellos, depuestas en tanto las armas con leal y sincera voluntad" (Benedicto XV, 1914, n. 3).

El Santo Padre no se cansó de exhortar a los países involucrados en la guerra a poner todos los medios necesarios para conseguir una paz duradera fundada en la justicia y el derecho, por ello, el 1 de agosto de 1917 enviaba la nota Dès le debut a todos los gobiernos de las naciones beligerantes en la cual les expresaba cuáles podrían ser las bases para una negociación: "Queremos ahora descender a proposiciones más concretas y prácticas, e invitar a los gobiernos de los pueblos beligerantes a ponerse de acuerdo sobre los puntos siguientes, que parece deben ser las bases de una paz justa y duradera, dejándoles el cuidado de precisarlas y completarlas" (Benedicto XV, 1917, n. 4).

Los puntos que Benedicto XV proponía eran los siguientes: la fuerza del derecho debe sustituir a la fuerza de las armas, para ello debe haber disminución de armamentos e institución de arbitraje internacional; facilitar el uso de las vías de comunicación respetando la libertad y comunidad 
de los mares; el principio de condonación debe regir la cuestión de las indemnizaciones y reparaciones de guerra; restitución recíproca de los territorios ocupados; los desacuerdos territoriales particulares deben ser examinados con calma teniendo en cuenta la justicia y el bien común. Infortunadamente este mensaje no fue acogido por los gobiernos beligerantes. Sería la historia la que años más tarde le daría la razón al Papa della Chiesa cuando el mundo constate las semillas de odio y de ruptura que dejó el tratado de Versalles, con el que finalizó la Primera Guerra Mundial.

Las terribles consecuencias de la guerra no solo afectan las construcciones y la infraestructura de las naciones en conflicto, sino que sobre todo afectan a personas concretas. Hombres y mujeres, nińos y viejos que ven destruidos sus derechos más elementales. El Magisterio pontificio de Benedicto XV (como el de sus predecesores) se preocupó también por el sufrimiento de miles de personas que lo padecían. El 24 de noviembre de 1919 el Papa dirige su encíclica Paterno iam diu animo a todos los obispos y fieles de la Iglesia exhortándolos a ayudar a los más necesitados de Europa después de la guerra: "de todas partes se nos informa que los pueblos mencionados sufren frecuentemente tanta escasez de alimento y vestido que Nuestra mente apenas es capaz de imaginarse lo extremado de la situación" (Benedicto XV, 1919, n. 1). Específicamente el Sumo Pontífice lanza una campaña de ayuda por los niños de la Europa central pues

en el entretanto, se pierde y se arruina miserablemente la salud de los cuerpos debilitados, en especial la de los nińos. Su desgracia nos afecta tanto más vehementemente cuanto que no sólo son inocentes e ignaros de la guerra destructora que ensangrentó casi todo el orbe de la tierra, sino que son, además, los progenitores de las nuevas generaciones (Benedicto $\mathrm{XV}, 1919$, n. 2).

Una vez terminada la Guerra y firmados los pactos que ponían fin al conflicto el Papa no dudó en llamar la atención sobre lo esencial, y en su encíclica Pacem, Dei munus advertía de una manera casi profética:

Si bien en casi todas partes se ha puesto, en cierta manera, fin a la guerra; si se han firmado tratados de paz, no han sido, empero, extirpados los gérmenes de las antiguas discordias; y no dudáis, Venerables hermanos que toda paz es inestable, ineficaces todos los tratados -no obstante 
las prolongadas y laboriosas negociaciones de sus autores y el carácter sagrado de los convenios suscritos- mientras no se apacigüen los odios, las enemistades mediante una reconciliación inspirada en la caridad mutua (Benedicto XV, 1920, n. 1).

La paz, nos recuerda el Sumo Pontífice, no es fruto ni obra de un acuerdo, la paz no consiste en el equilibrio entre las fuerzas de los adversarios, ni la simple ausencia de guerra. La verdadera paz se funda en una correcta visión del ser humano y requiere para su edificación la justicia y la caridad. Dicha caridad no solo es responsabilidad de cada persona en concreto, sino que debe ser el pilar de una familia de naciones:

En cuanto todo sea restablecido según las normas de la justicia y de la caridad y cuando las naciones se hayan reconciliado, muy de desear es, Venerables Hermanos, que todos los Estados, dejando de lado todos sus mutuos recelos, se unan para no formar más que una sola familia, con la mira de defender sus libertades particulares y de mantener el orden social. (Benedicto XV, 1920, n. 13)

Para construir una sociedad pacífica y lograr el desarrollo integral de las naciones resulta esencial el compromiso por la defensa y la promoción de los derechos humanos.

\section{PÍO XI Y LA RECIA DEFENSA DE LOS DERECHOS HUMANOS ANTE LAS AMENAZAS DE LAS IDEOLOGÍAS}

Pocos años después de finalizada la Primera Guerra Mundial el cardenal Aquiles Ratti, quien toma el nombre de Pío XI (1922 - 1939), sucede al papa Benedicto XV en la Cátedra de San Pedro. Como su predecesor, el papa Ratti también manifestará sus preocupaciones por el establecimiento de una verdadera paz mundial. En la primera encíclica de su pontificado Ubi arcano publicada el 23 de diciembre de 1922 dirá con claridad:

Nadie hay que ignore que ni para los hombres en particular, ni para la sociedad, ni para los pueblos, se ha conseguido todavía una paz verdadera 
después de la guerra calamitosa, y que todavía se echa de menos la tranquilidad activa y fructuosa que todos desean. Pero de este mal es preciso ante todo examinar la grandeza y gravedad, e indagar después las causas y las raíces, si se quiere, como Nos queremos, poner el oportuno remedio. (n. 1)

De nuevo se evidencia en el Magisterio pontificio lo importante que resulta la búsqueda de las causas que originan un conflicto bélico, y ante todo, las relacionadas con situaciones de injusticia, de miseria y de vulneración de los derechos humanos, sobre las cuales hay que intervenir con el objeto de eliminarlas y poder así edificar una paz verdadera.

Pío XI será conocido por su valiente defensa de los derechos del hombre ante los atropellos cometidos por los regímenes totalitarios. Duras y muy claras son sus críticas contra los excesos del nacional-socialismo alemán, del fascismo italiano, del comunismo soviético, así como del gobierno mexicano de entonces que conculcaba los derechos humanos y del gobierno de la segunda república española que venía violentando el derecho a la libertad religiosa.

El 18 de noviembre de 1926 en la encíclica Iniquis afflictisque el Papa denuncia los atropellos y la dura situación de los católicos en México ${ }^{3}$. No duda el Santo Padre en señalar que "por una ley promulgada por el presidente en julio de este año, ya entonces no le queda a la Iglesia casi nada de los derechos y de la libertad en aquellas regiones; el ejercicio del sagrado ministerio de tal manera se halla impedido, que es castigado con penas severísimas como un crimen capital" (Pío XI, 1926, n. 9). La libertad religiosa, derecho humano fundamental, es defendida con ahínco por el Sumo Pontífice. El Magisterio de la Iglesia es claro en afirmar que la

3 Sobre la situación de la Iglesia católica en México el papa Pío XI escribirá dos encíclicas más: Acerba animi anxitudo el 29 de septiembre de 1932 en la que vuelve a expresar su preocupación por la vulneración de los derechos de los católicos en esta nación americana y denuncia la persecución contra los católicos. En dicha encíclica el papa también elogia el heroísmo demostrado por sacerdotes y laicos. La otra carta Firmissimam constantiam es escrita el 28 de marzo de 1937 y en ella el Santo Padre felicita a los católicos mexicanos por su constancia en medio de las persecuciones y los alienta y anima a perseverar en sus convicciones. 
dignidad de la persona supone que la libertad religiosa sea reconocida en los ordenamientos jurídicos. Este reconocimiento ayudará a la protección de la persona frente a cualquier intento de coacción.

Al cumplirse los cuarenta años de la publicación de la magistral encíclica sobre la cuestión obrera, Rerum novarum, de León XIII, el papa Pío XI escribe la Quadragesimo anno el 15 de mayo de 1931. En esta encíclica el Santo Padre recuerda que aunque la economía y la moral tienen cada una sus propios principios, "es un error afirmar que el orden económico y el orden moral están tan separados y son tan ajenos entre sí, que aquél no depende para nada de éste" (Pío XI, 1931a, n. 42). No podemos olvidar las injusticias que pueden darse, y de hecho se han dado, cuando las leyes económicas pretenden una total autonomía de la ética y la moral. En esta encíclica social el Papa profundiza principalmente en cinco temas: el derecho de propiedad y su carácter individual y social; las relaciones entre el capital y el trabajo y la justa distribución; el problema de la pobreza y la mala repartición de las riquezas; el salario justo; la necesaria restauración del orden social que implica una necesaria renovación moral. Después de esto llama la atención el papa Ratti sobre la necesaria referencia de los hombres a la ley divina y a la ley natural:

Si todos, en todas partes y siempre, observaran esta ley, pronto volverían a los límites de la equidad y de la justa distribución no sólo la producción y adquisición de las cosas, sino también el consumo de las riquezas, que hoy con frecuencia tan desordenado se nos ofrece; al egoísmo, que es la mancha y el gran pecado de nuestro días, sustituiría en la práctica y en los hechos la ley suavísima pero a la vez eficacísima de la moderación cristiana, que manda al hombre buscar primero el reino de Dios y su justicia. (Pío XI, 1931a, n. 136)

Ante los diversos excesos de autoridad, Pío XI escribe en junio de 1931 la encíclica Non abbiamo bisogno, contra el fascismo italiano. En dicha carta el papa Ratti condena la estatolatría del régimen y cuestiona sus métodos totalitarios, su manipulación de la prensa, la constante ofensa a la justicia y a la verdad. El Papa también critica las constantes medidas policivas acompañadas de violencia e irreverencia, la prohibición del derecho de libre asociación así como los atentados contra la libertad de conciencia y religiosa. Dice el Papa: "Las doctrinas erróneas que acabamos de señalar y deplorar 
se han presentado más de una vez durante los últimos años, y como es notorio Nos no hemos faltado jamás, con la ayuda de Dios, a Nuestro deber apostólico de examinarlas y oponer las debidas observaciones y llamamientos a las verdaderas doctrinas" (Pío XI, 1931b, n. 28).

La legislación abiertamente anticatólica promulgada durante los primeros años de la segunda república española y los abusos contra la Iglesia y los católicos en esta nación fueron los motivos por los cuales el Santo Padre escribe el 3 de junio de 1933 la encíclica Dilectissima nobis. En esta carta el Papa recuerda que la Iglesia no es contraria a ninguna forma justa de gobierno, sin embargo recuerda que sobre todo un gobierno debe respetar el derecho y la dignidad del ser humano, ya sea una monarquía, una república, una aristocracia o una democracia. En este sentido no es justo un gobierno que apoya la violencia contra quienes opinan distinto, que despoja arbitrariamente de las propiedades a los que no son de su partido, que deja profanar y saquear templos hiriendo el sentimiento religioso de los ciudadanos, que prohíbe la libre asociación y suprime las órdenes y congregaciones religiosas. Contra estos atentados y vulneración de derechos alzó la voz el papa Pío XI.

El domingo 14 de marzo de 1937 escribe el Santo Padre la encíclica Mit brennender sorge (Con ardiente preocupación) en la que con vehemencia expone sus críticas contra el totalitarismo nazi y sus doctrinas: "Solamente espíritus superficiales pueden caer en el error de hablar de un dios nacional y de una religión nacional, e inventar la loca empresa de aprisionar en los límites de un solo pueblo y en la estrechez de una sola raza a Dios" (Pío XI, 1937a, n. 15). El Papa retoma en esta carta el tema del derecho natural, sobre el cual debe estar fundada toda ley positiva. Dice el Papa que la legitimidad de toda norma jurídica así como la obligación de cumplirla derivan del derecho natural: "Las leyes humanas que estén en abierta contradicción con el derecho natural se hallan afectadas de vicio original, que no se remedia ni con la violencia ni con el despliegue de fuerzas externas" (Pío XI, 1937a, n. 35). También afirma Pío XI con mucha firmeza que "el hombre, en cuanto persona, posee derechos otorgados por Dios, que deben ser tutelados contra todo atentado por parte de la comunidad de negarlos, abolirlos o impedir sus ejercicio" (Pío XI, 1937a, n. 35). El Sumo Pontífice expresa con mucha claridad que la persona humana posee unos derechos y una dignidad inherente a su naturaleza y que éstos no pueden depender 
del gusto o del capricho de un Estado, cualquiera que sea. Dichas ideas chocaban radicalmente con el nacional-socialismo, que acaparaba para sí mismo el derecho de dirigir las conciencias de los ciudadanos alemanes; sin embargo, cuando se rechaza la idea del derecho natural, la persona humana queda indefensa frente a cualquier atentado, por ello señala el Papa que,

al despreciar esta verdad, se pierde de vista que el verdadero bien común, en último término, es determinado y conocido mediante la naturaleza del hombre con su armónico equilibrio entre derecho personal y vínculo social, como también por el fin de la sociedad señalado por la misma naturaleza humana (Pío XI, 1937a, n. 35).

A solo unos cuantos días de haber publicado la Mit brennender sorge, el Papa se pronuncia en contra del totalitarismo soviético, publicando la carta encíclica Divini Redemptoris en la que hace una crítica al marxismo y a su visión antropológica reduccionista. El comunismo empobrece a la persona humana, pues es un sistema que le niega los derechos y la dignidad ontológicamente inherentes a su ser, despoja al hombre de su libertad y reduce a la persona humana "a una simple rueda y engranaje del sistema" (Pío XI, 1937b, n. 10). También denuncia Pío XI la terrible conflictividad de este sistema, que no soluciona los problemas de la sociedad sino que los agudiza con la violencia que genera: "hemos mostrado que los medios para salvar al mundo actual del desastre a que el liberalismo amoral nos ha llevado, no consisten en la lucha de clases y en el terror, ni tampoco en el abuso autocrático del poder estatal, sino en la penetración de la justicia social" (Pío XI, 1937b, n. 31). Resulta muy interesante que el Santo Padre no se limita tan solo a señalar los errores del comunismo sino que también hace propuestas muy reales para la solución de los conflictos. En este sentido, Pío XI propone cuál debe ser la tarea del Estado:

Debe empeñarse en crear las condiciones materiales de vida sin las cuales no puede subsistir una sociedad ordenada, y en procurar trabajo especialmente a los padres de familia y a la juventud. Para ese fin indúzcase a las clases pudientes, por la urgente necesidad del bien común, a hacerse cargo de los gravámenes sin los que no puede salvarse a la sociedad humana ni salvarse ellas mismas. Mas las iniciativas que el Estado tome para este fin deben ser de tal naturaleza que alcancen realmente a los que tienen entre sus manos los mayores capitales y los van continuamente aumentando con grave perjuicio de los demás (Pío XI, 1937b, n. 81). 


\section{PÍO XII ANTE EL HORROR DE LA SEGUNDA GUERRA MUNDIAL}

A Pío XI lo sucede su amigo personal y hasta entonces Secretario de Estado, el cardenal Eugenio Pacelli, quien en honor a su antecesor tomará el nombre de Pío XII (1939 - 1958). El Papa Pío XII, quien vivió la tragedia de la Segunda Guerra mundial, será un gran defensor de los derechos humanos y un infatigable predicador en favor de la paz mundial y en contra de los excesos de los totalitarismos. Desde la Summi Pontificatus -su primera encíclica- publicada el 20 de octubre de 1939 el Santo Padre evidenciará su preocupación por situar a la persona humana como el centro de la vida social. Pío XII se esfuerza por destacar que siempre, el Estado debe estar al servicio de la persona y nunca la persona al servicio del Estado, como pretendían los totalitarismos de su tiempo. Por ello, frente a las pretensiones ilimitadas de éstos, propone la revalorización de la dignidad inviolable de la persona humana, imagen de Dios. Ése es para el Papa el principal y definitivo argumento contra los abusos que se venían cometiendo, pues

dónde se rechaza la dependencia del derecho humano respecto del derecho divino, donde no se hace apelación sino a una idea incierta de autoridad meramente terrena y se reivindica una autonomía fundada únicamente en la moral utilitaria, allí, el mismo derecho humano pierde justamente en sus aplicaciones más difíciles la fuerza moral, que es la condición esencia para ser reconocido y exigir sacrificios (Pío XII, 1939a, n. 42).

Según el Papa Pacelli, solo se logrará proteger realmente a la persona del despotismo del Estado recurriendo a la ley natural; no podemos olvidar que la raíz de los problemas de nuestro tiempo radica en el olvido de la ley natural y de la ley divina:

Y ante todo, es cierto que la raíz profunda y última de los males que deploramos en la sociedad moderna, es el negar y rechazar, así en la vida individual como en la vida social y en las relaciones internacionales; el desconocimiento, en una palabra, tan extendido en nuestros tiempos y el olvido de la misma ley natural, la cual tiene su fundamento en Dios (Pío XII, 1939a, n. 20).

En contra del totalitarismo estatal que abusa de los derechos del ser humano el Papa dirá: 
Considerar el Estado como fin al que debe subordinarse y dirigirse todo, podría tener nada más que consecuencias nocivas para la prosperidad verdadera y estable de las naciones. Y esto, sea que este dominio ilimitado se atribuya al Estado como mandatario de la nación, del pueblo, o sólo de una clase social; sea que lo reclame el Estado como absoluto señor, independientemente de todo mandato. (Pío XII, 1939a, n. 46)

También en esta carta Pío XII advertirá sobre el peligro que los totalitarismos, cualquiera que sea su nombre, traen para el orden internacional:

La concepción que atribuye al Estado una autoridad casi infinita no sólo es, venerables hermanos, un error pernicioso a la vida interna de las naciones, a su prosperidad y al creciente y ordenado incremento de su bienestar; sino que además causa dańos a las relaciones entre los pueblos, porque rompe la unidad de la sociedad sobrenatural, quita su fundamento y valor al derecho de gentes, conduce a la violación de los derechos de los demás y hace difícil la inteligencia y la convivencia pacífica. (Pío XII, 1939a, n. 53)

La búsqueda de la paz en medio de la guerra es también un objetivo que persigue el Papa en la Summi pontificatus, por ello recuerda que el fundamento de la paz no se encuentra en medios externos. La esperanza no puede estar fundada según él "en el encuentro guerrero y en su desenlace final" pues la experiencia nos enseña que a veces los pactos finales (determinados por los sufrimientos padecidos y motivados por la sed de revancha o de venganza) son semilla de nuevos odios. Dice Pío XII:

No, venerables hermanos, la salvación de los pueblos no viene de los medios externos, de la espada, que puede imponer condiciones de paz, pero no crea la paz. Las energías que deben renovar la faz de la tierra, tienen que proceder del interior, del espíritu. El orden nuevo del mundo, de la vida nacional e internacional, una vez que cesen las amarguras y las crueles luchas actuales, no deberá en adelante apoyarse sobre la incierta arena de normas mudables y efímeras, abandonadas al arbitrio del egoísmo colectivo e individual. Deben más bien alzarse sobre el fundamento inconcluso, sobre la roca inconmovible del derecho natural y de la revelación divina. (Pío XII, 1939a, n. 60)

Vale la pena recordar que unas semanas antes del estallido de la guerra, el Papa había dirigido al mundo unas proféticas palabras. El jueves 24 de 
agosto de 1939 Pío XII hizo un llamado (por medio de un radiomensaje), invitando a hacer todos los esfuerzos posibles por evitar la guerra, y afirmó:

La justicia se abre camino por la fuerza de la razón, no por la fuerza de las armas (...). Nada se pierde con la paz; pero todo puede perderse con la guerra (...). Que nos escuchen los fuertes para no caer en la debilidad de la injusticia. Que nos escuchen los poderosos, si quieren que su poder no se convierta en destrucción, sino en ayuda a los pueblos y en protección de la tranquilidad en el orden y en el trabajo. (Pío XII, 1939b)

Desafortunadamente el llamado del Santo Padre no fue acogido por los líderes de entonces y el mundo se precipitó hacia la Segunda Guerra Mundial.

El 1 de junio de 1941 el Papa sorprende de nuevo comunicándose por medio de otro radiomensaje $e^{4}$ La solennitá della pentecoste, en ocasión del cincuentenario de la encíclica Rerum novarum: "Nos servimos hoy de este maravilloso medio para llamar la atención del mundo católico sobre una conmemoración que merece esculpirse con caracteres de oro en los fastos de la Iglesia" (Pío XII, 1941a, n. 3). En dicho radiomensaje Pío XII repasará algunos temas fundamentales esbozados en el documento de León XIII, que siguen manteniendo una actualidad constante al contener verdades fundamentales sobre el ser humano, sus derechos y su naturaleza.

Celebrando el aniversario del texto leoniano, el Papa Pacelli habla sobre el derecho a la propiedad: "todo hombre como viviente dotado de razón, tiene de hecho por naturaleza, el derecho fundamental de usar los bienes materiales de la tierra, aunque se haya dejado a la voluntad humana y a las formas jurídicas de los pueblos el regular más particularmente la actuación práctica" (Pío XII, 1941a, n. 13); la misión de Estado frente al bien común: "tutelar el intangible campo de los derechos de la persona humana y facilitarle el cumplimiento de sus deberes ha de ser oficio esencial de todo poder público" (Pío XII, 1941a, n. 15); el derecho al trabajo: "Al deber personal del trabajo impuesto por la naturaleza corresponde y sigue el derecho natural de

4 Esta novedosa manera de comunicarse será muy común durante todo el pontificado de Pío XII. El deseo de que sus mensajes lleguen de manera directa a muchas más personas hará que muchos de los más importantes mensajes del papa Pacelli hayan sido pronunciados por este medio. Los radiomensajes de Navidad durante la guerra son un ejemplo de ello. 
cada individuo para convertir el trabajo en el medio de proveer a su propia vida y a la de sus hijos" (Pío XII, 1941a, n. 19); señala que las normas estatales deben hacer realizable el ejercicio de los derechos fundamentales: "el derecho al verdadero culto a Dios; el derecho al matrimonio; el derecho de los cónyuges, del padre y de la madre, a realizar su vida conyugal y doméstica; el derecho a una razonable libertad en la elección de estado y en seguir una verdadera vocación" (Pío XII, 1941a, n. 21). Este documento hace parte del llamado constante, presente en los textos del magisterio, al necesario compromiso de todos por edificar una cultura de vida en la que se respete la dignidad intrínseca de todo ser humano.

Los discursos y radiomensajes pronunciados por Pío XII en el contexto de la Navidad, durante los terribles años de la guerra, son un evidente ejemplo de su compromiso por la defensa de los derechos humanos. El contenido de estos mensajes es un valioso tesoro del magisterio de la Iglesia:

In questo giorno es el discurso de 1939 en el que el Papa Pacelli denuncia los abusos de la guerra que apenas unos meses atrás se había encendido y los actos atroces que comenzaban a darse:

La premeditada agresión contra un pueblo pequeńo, laborioso y pacíico, con el pretexto de una amenaza ni existente ni querida y ni siquiera posible; las atrocidades (quienquiera que las haya cometido) y el uso ilícito de medios de destrucción incluso contra los no combatientes y los fugitivos, contra los ancianos, las mujeres y los niños; el desprecio de la dignidad, de la libertad y de la vida humana. (Pío XII, 1939c, n. 7)

Años más tarde, en 1949, los Convenios de Ginebra plasmarán muchos de estos postulados propuestos por el Santo Padre. En sus mensajes, el Papa propone los postulados fundamentales para una paz justa: 1. Asegurar el derecho a la vida y a la independencia de todas las naciones (grandes, pequeñas, poderosas y débiles); 2. Renunciar a la carrera armamentista; 3. Constituir instituciones jurídicas que sirvan para garantizar el leal y fiel cumplimiento de los tratados; 4. Respetar las justas exigencias de las naciones, pueblos y minorías étnicas en procura de encontrar un verdadero equilibrio entre las naciones; 5. Revigorizar el espíritu de responsabilidad, de justicia y de amor que sea capaz de darle vida a la letra muerta de los tratados internacionales. 
En Grazie, el discurso navideño de 1940 dirigidos a los miembros del sacro colegio y de la Prelatura Romana, el Papa enuncia las bases indispensables del nuevo orden mundial que debía surgir después de la guerra. Solo en un orden social en el que prime la justicia, el respeto por los derechos humanos y por los derechos de las naciones, será posible vivir en paz. Los presupuestos indispensables para este ordenamiento son: 1 . La victoria sobre el odio que divide a los pueblos, que lleve a la búsqueda de los ideales de "veracidad, justicia, cortesía y cooperación al bien, y ante todo, el sublime ideal sobrenatural del amor fraterno traído por Cristo al mundo" (Pío XII, 1940, n. 26); 2. La victoria sobre la desconfianza que lleve "a aquella fidelidad en la observancia de los pactos sin la que no es posible una tranquila convivencia de los pueblos y, sobre todo, una coexistencia de pueblos poderosos y pueblos débiles" (Pío XII, 1940, n. 26); 3. La victoria sobre el principio "de que la utilidad es la base y regla del derecho y de que la fuerza crea el derecho" (Pío XII, 1940, n. 26); 4. La victoria sobre los gérmenes de conflictos, es decir sobre las diferencias abrumadoras en el campo de la economía mundial; 5. La victoria sobre el espíritu del egoísmo.

El radiomensaje navideño de 1941, Nell'alba, está marcado por la tristeza de tres ańos de una terrible guerra: "es verdad, amados hijos, que, si nuestros ojos no mirasen más allá de la materia y de la carne, apenas si podrían encontrar motivo alguno de consuelo" (Pío XII, 1941b, n. 4) y constituye un nuevo llamado a construir un orden fundado en principios morales:

Este nuevo orden que todos los pueblos anhelan ver realizado después de las pruebas y ruinas de esta guerra, ha de alzarse sobre la roca indestructible e inmutable de la ley moral, manifestada por el mismo Creador mediante el orden natural y esculpida por Él en los corazones de los hombres con caracteres indelebles. (Pío XII, 1941b, n. 17)

El Papa insiste sobre algunos presupuestos esenciales para un nuevo orden en el que impere el derecho y la justicia: 1. Libertad, integridad y seguridad de todas las naciones, indistintamente de su territorio y poder militar; 2. Respeto por las peculiaridades culturales y lingüísticas de las minorías; 3. Participación de todos en los bienes de la tierra que asegure la no exclusión de las naciones más pobres; 4. Limitación progresiva y adecuada de los armamentos, respeto y fidelidad al principio jurídico de "pacta sunt servanda"; y 5. Respeto a la religión. 
Pío XII, en Con sempre, el radiomensaje navideño de 1942 hará un esbozo de los elementos necesarios para alcanzar la paz y el orden en la sociedad humana. El Santo Padre recuerda que el origen y el fin último de la vida social ha de ser la conservación, el desarrollo y el perfeccionamiento de la persona humana; en este sentido un Estado que niegue estos principios en su legislación "en vez de servir a la sociedad, le daña; lejos de promover y fomentar el pensamiento social y de realizar sus ideales y esperanzas, le quita todo valor intrínseco, sirviéndose de él como de una frase utilitaria" (Pío XII, 1942, n. 10). En este mensaje, el Papa afirma que, aquel que desee una sociedad más justa, una sociedad en paz que quiera respetar al ser humano, debe contribuir a devolver a la persona humana la dignidad que Dios le concedió desde el principio y en este sentido apoyar

el respeto y la práctica realización de los siguientes derechos fundamentales de la persona: Derecho a mantener y desarrollar la vida corporal, intelectual y moral, y particularmente el derecho a una formación y educación religiosa; el derecho al culto de Dios privado y público, incluida la acción caritativa religiosa; el derecho, en principio, al matrimonio y a la consecución de su propio fin; el derecho a la sociedad conyugal y doméstica; el derecho a trabajar como medio indispensable para el mantenimiento de la vida matrimonial; el derecho a un uso de los bienes materiales consciente de sus deberes y de las limitaciones sociales. (Pío XII, 1942, n. 34).

El conjunto de derechos que el Papa Pío XII señala como fundamentales de la persona humana será un agudo y certero trazado inicial de los que la Declaración de Derechos Humanos recogerá algunos años más tarde. En este mismo mensaje, el Santo Padre afirma que una sociedad justa debe ser edificada sobre la defensa de la institución familiar y que

Defienda la indisolubilidad del matrimonio; dé a la familia, célula insustituible del pueblo, espacio, luz, tranquilidad, para que pueda cumplir la misión de perpetuar la nueva vida y de educar a los hijos [...] cuide de procurar a cada familia un hogar en donde una vida doméstica sana material y moralmente llegue a desarrollarse con toda su fuerza y valor; procure que los locales de trabajo y los domicilios no estén tan separados que hagan del jefe de familia y del educador de los hijos casi un extrańo en su propia casa (Pío XII, 1942, n. 34). 
Como se puede apreciar, lo que afirma el Papa constituye todo un elenco de elementos que buscan fortalecer el núcleo base de la sociedad. Por otro lado, afirma el Sumo Pontífice que "como medio indispensable para el dominio del mundo, querido por Dios para su gloria, todo trabajo posee una dignidad inalienable $\mathrm{y}$, al mismo tiempo, un íntimo lazo con el perfeccionamiento de la persona" (Pío XII, 1942, n. 34). Señala también el Papa que una sociedad justa y en paz solamente se logrará en la medida en que exista en ella un ordenamiento jurídico que proteja a todos los miembros del Estado de cualquier tipo de arbitrariedad. Esto supone:

a) Un tribunal y un juez que reciban sus normas directivas de un derecho claramente formulado y circunscrito. b) Normas jurídicas claras, que no puedan ser tergiversadas con abusivas apelaciones a un supuesto sentimiento popular y con meras razones de utilidad. c) El reconocimiento del principio que afirma que también el Estado y sus funcionarios y las organizaciones de él dependientes están obligados a la reparación y a la revocación de las medidas lesivas de la libertad, de la propiedad, del honor, del mejoramiento y de la vida de los individuos. (Pío XII, 1942, n. 34)

Por último, afirma el Santo Padre que, la estrella de la paz aparecerá sobre la sociedad humana en la medida en que ayudemos a dirigir el Estado y todo su poder al servicio de la sociedad y al pleno respeto de la persona.

En el radiomensaje navideño de 1944 Benignitas et humanitas, el Santo Padre se preocupa por establecer las características esenciales de una sana democracia en la que la persona humana pueda desplegar sus derechos libremente. Para Pío XII una sana democracia será aquella

fundada sobre los inmutables principios de la ley natural y de las verdades reveladas, será resueltamente contraria a aquella corrupción que atribuye a la legislación del Estado un poder sin freno ni límites, y que hace también del régimen democrático, a pesar de las contrarias, pero vanas apariencias, un puro y simple sistema de absolutismo. (Pío XII, 1944, n. 28)

De nuevo nos recuerda el Papa que la legislación de un Estado tiene que respetar y conformarse con los dictados de la ley natural. Este criterio nos ayudará a discernir cuándo estamos ante un gobierno justo y cuándo ante uno injusto, no importa si es elegido democráticamente. 
La preocupación por la defensa de la dignidad de la persona humana fue una lucha constante durante el pontificado de este gran Papa. Pío XII saludó con simpatía los esfuerzos que se hacían para incorporar en las legislaciones los derechos humanos. En 1950, durante el Discurso sobre la verdadera noción del Estado afirmó:

Hay ciertos derechos y libertades del individuo o de la familia que el Estado debe siempre proteger y que nunca puede violar o sacrificar a un pretendido bien común. Nos referimos, para citar solamente algunos ejemplos, al derecho al honor y a la buena reputación, al derecho y a la libertad de venerar al verdadero Dios, al derecho originario de los padres sobre sus hijos y su educación. El hecho de que algunas constituciones hayan adoptado estas ideas es una promesa feliz, que Nos saludamos con alegría, como la aurora de una renovación en el respeto a los verdaderos derechos del hombre, tal como han sido queridos y establecidos por Dios. (Pio XII, 1950, n. 6)

El Papa Pacelli estuvo preocupado por la eficacia real de las declaraciones, pues para él, lo fundamental no consiste en que los derechos estén escritos en una declaración, sino que de verdad, la dignidad y derechos de los seres humanos sean respetados. A propósito de ello, el Papa expresa su preocupación por el papel de la ONU en el mundo. Acerca de esto afirma en el radiomensaje navideño de 1956, Linesauribile mistero:

Nadie espera o pide lo imposible, ni siquiera de las mismas Naciones Unidas; pero se habría podido esperar que su autoridad hubiera tenido su peso, al menos mediante los observadores, en los lugares en extremo peligro por los valores esenciales del hombre. Por más que sea digno de reconocimiento que la ONU condene violaciones graves de los derechos de los hombres y de pueblos enteros, cabría, sin embargo, desear que, en semejantes casos, a Estados que rechazan incluso la admisión de observadores -demostrando de ese modo tener de la soberanía del Estado un concepto que mina los fundamentos mismos de la ONU- no se les permita el ejercicio de sus derechos de miembros de la Organización misma. Ésta debería tener, además, el derecho y el poder de prevenir toda intervención militar de un Estado en otro, cualquiera que fuera el pretexto con que se intentara efectuar, no menos que de asumir con suficientes fuerzas de policía la tutela del orden en el Estado amenazado. (Pío XII, 1956, n. 43) 


\section{CONCLUSIÓN}

A lo largo de este recorrido por el magisterio de la Iglesia en los asuntos concernientes a los derechos humanos nos hemos encontrado con una grata realidad: el compromiso real y concreto por el ser humano por parte de la Iglesia católica y de quienes han tenido la responsabilidad de guiarla durante la Gran Guerra del siglo XX. Hemos podido constatar que la preocupación por los derechos y deberes del hombre no constituye solamente una serie de ricas y elevadas reflexiones, ni se queda, mucho menos, en vagas especulaciones, sino que constantemente vemos la manera como se involucra dicho magisterio en las circunstancias concretas, con los hombres y mujeres de carne y hueso que a lo largo de la historia sufren atentados contra su dignidad y sus derechos fundamentales.

El Estado justo es aquel que, consciente de la naturaleza social del ser humano, se hace garante del bien común y de los derechos humanos. En el magisterio pontificio hemos podido ver las continuas y persistentes exhortaciones a los gobernantes para que busquen en todo momento la justicia. De igual manera, hemos sido testigos de la valentía con la que han denunciado los atropellos de las ideologías y de los gobiernos (indistintamente sean de izquierda o de derecha) que abusando del poder, han ejercido su autoridad con despotismo y arbitrariedad.

Las guerras mundiales y sus consecuencias atraviesan con secuelas de dolor el magisterio pontificio de estos años, por ello la reflexión sobre la guerra y la búsqueda de la paz verdadera representan un hito imoprtante en las reflexiones. En las enseñanzas de los pontífices vemos que la verdadera paz no se basa en una mera ausencia de guerra sino que se afirma en una recta visión del hombre y por consiguiente, en un verdadero desarrollo que va mas allá de lo técnico y que se plasma en la edificación de un mundo verdaderamente humano.

\section{LISTA DE REFERENCIAS}

Benedicto XV, Papa. (1914). Carta Encíclica Ad beatissimi. Roma: Editrice Vaticana. Benedicto XV, Papa. (1917). Carta Dès le debut. Roma: Editrice Vaticana. 
Benedicto XV, Papa. (1919). Carta Encíclica Paterno iam diu. Roma: Editrice Vaticana.

Benedicto XV, Papa. (1920). Carta Encíclica Pacem Dei munus. Roma. Recuperado de http://www.vatican.va/holy_father/benedict_xv/encyclicals/documents/ hf_ben-xv_enc_23051920_pacem-dei-munus-pulcherrimum_sp.html

Martín Artajo, A. (1958). Doctrina Pontificia, Escritos políticos. Madrid: BAC.

Pío XI, Papa. (1922). Carta Encíclica Ubi arcano. Roma: Editrice Vaticana.

Pío XI, Papa. (1926). Carta Encíclica Iniquis afflictisque. Roma: Editrice Vaticana.

Pío XI, Papa. (1931a). Carta Encíclica Quadragesimo anno. Roma. Recuperado de http://www.vatican.va/holy_father/pius_xi/encyclicals/documents/hf_pxi_enc_19310515_quadragesimo-anno_sp.html

Pío XI, Papa. (1931b). Carta Encíclica Non abbiano bisogno. Roma. Recuperado de http://www.vatican.va/holy_father/pius_xi/encyclicals/documents/hf_pxi_enc_19310629_non-abbiamo-bisogno_sp.html

Pío XI, Papa. (1933). Cara Encíclica Dilectissima novis. Roma. Recuperado de http://www.vatican.va/holy_father/pius_xi/encyclicals/documents/hf_pxi_enc_19330603_dilectissima-nobis_sp.html

Pío XI, Papa. (1937a). Carta Encíclica Mit brennender sorge. Roma. Recuperado de http://www.vatican.va/holy_father/pius_xi/encyclicals/documents/hf_pxi_enc_14031937_mit-brennender-sorge_sp.html

Pío XI, Papa. (1937b). Carta Encíclica Divini Redemptoris. Roma. Recuperado de http://www.vatican.va/holy_father/pius_xi/encyclicals/documents/hf_pxi_enc_19370319_divini-redemptoris_sp.html

Pío XII, Papa. (1939a). Carta Encíclica Summi Pontificatus. Roma. Recuperado de http://www.vatican.va/holy_father/pius_xii/encyclicals/documents/hf_pxii_enc_20101939_summi-pontificatus_sp.html

Pío XII, Papa. (1939b). Radiomensaje Un’ora grave. Roma. Recuperado de http:// www.vatican.va/holy_father/pius_xii/speeches/1939/documents/hf_pxii_spe_19390824_ora-grave_it.html

Pío XII, Papa. (1939c). Discurso In questo giorno. Roma. Recuperado de http:// www.vatican.va/holy_father/pius_xii/speeches/1939/documents/hf_pxii_spe_19391224_questo-giorno_sp.html 
Los derechos humanos y el magisterio de la Iglesia durante la gran guerra del siglo xx

Pío XII, Papa. (1940). Discurso Grazie. Roma. Recuperado de http://www. vatican.va/holy_father/pius_xii/speeches/1940/documents/hf_p-xii_ spe_19401224_venerabili-fratelli_sp.html

Pío XII, Papa. (1941a). Radiomensaje La solennitá della pentecoste. Roma. Recuperado de http://www.vatican.va/holy_father/pius_xii/speeches/1941/ documents/hf_p-xii_spe_19410601_radiomessage-pentecost_sp.html

Pío XII, Papa. (1941b). Radiomensaje Nell'alba. Roma. Recuperado de http:// www.vatican.va/holy_father/pius_xii/speeches/1941/documents/hf_pxii_spe_19411224_radiomessage-peace_sp.html

Pío XII, Papa. (1942). Radiomensaje Con sempre. Roma. Recuperado de http:// www.vatican.va/holy_father/pius_xii/speeches/1942/documents/hf_pxii_spe_19421224_radiomessage-christmas_sp.html

Pío XII, Papa. (1944). Radiomensaje Benignitas et humanitas. Roma. Recuperado de http://www.vatican.va/holy_father/pius_xii/speeches/1944/documents/ hf_p-xii_spe_19441224_natale_sp.html

Pío XII, Papa. (1950). Discurso sobre la verdadera noción del Estado. Roma: Editrice Vaticana.

Pío XII, Papa. (1956). Radiomensaje L'inesauríbile mistero. Roma. Recuperado de http://www.vatican.va/holy_father/pius_xii/speeches/1956/documents/ hf_p-xii_spe_19561223_natale_it.html 